Research Article

\title{
INFLUENCE OF WATER STRESS ON MORPHOLOGY, PHYSIOLOGY AND YIELD CONTRIBUTING CHARACTERISTICS OF RICE
}

\author{
M.Z. Hossain", S. Sikder, A. Husna, S. Sultana, S. Akhter \\ A. Alim and J.C. Joardar \\ Soil, Water and Environment Discipline, Khulna University, Bangladesh
}

\begin{abstract}
Water stress or drought is one of the main reasons behind the lower productivity of rice-a widely popular nutritious cereal crop and the staple food for a large portion of the world's population. A pot experiment was conducted to investigate the effect of water stress on three rice varieties e.g. Banglamoti, Vittiatash and Atash balam in a silty clay soil. To identify whether less water affects rice production, rice plants were cultivated under five different water treatments, $\mathrm{T}_{1}$ : flooding at $5 \mathrm{~cm}$ depth, $\mathrm{T}_{2}$ : flooding at $3 \mathrm{~cm}$ depth, $\mathrm{T}_{3}$ : saturated water condition, $\mathrm{T}_{4}$ : water content@75\% saturation, and $\mathrm{T}_{5}$ : water content @ $05 \%$ saturation, and were arranged in a completely randomized design with three replications. Morphology, yield and physiological parameters of the rice plants were evaluated. Treatment below saturation did not produce any yield for all the rice varieties studied. All the morphological parameters and yields (e.g. dry weight of plants, plant height, tiller number, panicle number, grain number, grain weight, 1000 seed weight, and harvest index) showed a lower value under water deficient condition. Relative water content and water use efficiency declined with declining water content which represented the variations in their physiological responses to water stress. The grain content per panicle as well as 1000 grain weight of the rice varieties was maximum at saturation condition. Highest harvest index was observed for Vittiatash rice variety at saturated condition. Flooding the soil with either $5 \mathrm{~cm}$ or $3 \mathrm{~cm}$ depth did not produce any significant change in the studied parameters which indicated that approximately $2 \mathrm{~cm}$ water can easily be curtailed which may not affect the production of rice.
\end{abstract}

Keywords: Rice, Water Stress, Morphology, Physiology, Yield

\footnotetext{
* Corresponding author: zaberhossain74@ yahoo.com
} 


\section{INTRODUCTION}

The scarcity of water, commonly known as water stress or drought, is an alarming global problem and one of the major constraints that severely limits the sustainable production of agricultural crops. Increasing the food demand with increasing population would have consequent impact on the yield index due to water deficit. Rice (Oryza sativa L.) is one of the most important cereal crops in the world and contributes $90-91 \%$ among the total food grain production in Asia (IRRI, 2012). It is the staple food crop in Bangladesh and more than $80 \%$ of the total agricultural lands are under rice cultivation (BBS, 2002). The shortage of irrigation water at the growing season or reproductive stage results in serious deterioration of rice yield (Suriyan et al., 2010). When plant is subjected to water stress, a varieties of physiological changes are occurred such as- reduction of transpiration rate, chlorophyll content in leaves, photosynthetic rate, pigment degradation, stomatal conductance, relative water content (RWC), water use efficiency (WUE) and resulting in decrease of plant growth (Tuna et al., 2010; Jahan et al., 2014). Moreover, under acute water stressed situation, toxic materials like reactive oxygen species (ROS) is produced at the time of photosynthesis and respiration, and combines with fats, nucleic acids, proteins resulting in damage of plant cells, protein denaturation, lipid peroxidation, DNA mutation. Response of water stress by rice plant largely depends on several factors, includes- the genotype of plant, duration and severity of stress, growth stage. In the period of early vegetative growth and flowering, if plants unable to receive sufficient water, it drastically inhibits floret initiation, plant height, tiller number, leaf area, grain filling and ultimately low grain production (Zhang et al., 2018; Yang, et al., 2019). Proper irrigation is the prerequisite of rice production and in Asian developing countries, over $80 \%$ of freshwater is used for irrigational purpose (IRRI, 2012). Currently about 1900 to 5000 liters of water is required to produce $1 \mathrm{~kg}$ of rice grain and it is speculated that, almost $10 \%$ of irrigated rice will face water scarcity by 2025 (Tuong et al., 2005).

For this reason, researches are conducting numerous experiments and have taken it as a challenge to find out the proper management techniques, appropriate or optimum quantity of water to irrigate a particular rice variety to avoid the use of excess water in rice cultivation. Such initiatives will ensure efficient use of water and help to achieve the motto of grow more crops per drop of water (Akram, 2013; Materu et al., 2018). Therefore, the objectives of this study were to investigate the effect of water stress on morphological, physiological characteristics and yield of three rice varieties, and a systematic evaluation was carried out to identify the rice variety which performs best under low irrigation condition that will help to minimize loss of excess water for rice cultivation.

\section{MATERIAL AND METHODS}

The experiment was conducted in front of the net house of field laboratory of Soil, Water and Environment Discipline, Khulna University, Bangladesh which is 
geographically located at N: $22^{\circ} 10^{\prime}$ north latitude and $89^{\circ} 20^{\prime}$ east latitude. The experimental site has silty clay texture. Surface soil $(0-15 \mathrm{~cm})$ was collected from this site and the characteristics of experimental soil are given in Table 1.

Table 1: General properties of experimental soil

\begin{tabular}{lc}
\hline \multicolumn{1}{c}{ Properties } & Values \\
\hline Soil moisture content $(\%)$ & 25 \\
Sand & 12.05 \\
Silt & 54.12 \\
Clay & 33.83 \\
Soil Textural Class & Silty clay \\
Particle density $\left(\mathrm{gcm}^{-3}\right)$ & 2.5 \\
Bulk density $\left(\mathrm{gcm}^{-3}\right)$ & 1.15 \\
Porosity $(\%)$ & 55 \\
pH & 7.80 \\
EC $\left(\mathrm{dSm}^{-1}\right)$ & 0.13 \\
\hline
\end{tabular}

The collected soil was dried under the sun followed by crushing, mixed thoroughly and $8 \mathrm{~kg}$ soil was put in each of the 12L plastic pots. The pot soil was fertilized with urea, Triple Super Phosphate (TSP), Muriate of Potash (MOP) and gypsum as sources of $\mathrm{N}, \mathrm{P}, \mathrm{K}$ and $\mathrm{S}$ at the rate of $100 \mathrm{~kg} \mathrm{~N}, 60 \mathrm{~kg} \mathrm{P}_{2} \mathrm{O}_{5}, 75 \mathrm{~kg} \mathrm{~K}_{2} \mathrm{O}$ and $20 \mathrm{~kg} \mathrm{~S}$ $\mathrm{ha}^{-1}$, respectively (BARC, 2012). The whole amount of TSP, MOP, gypsum and $1 / 3^{\text {rd }}$ of urea was applied prior to final preparation of the pots. The remaining $2 / 3^{\text {rd }}$ urea was top dressed in two equal installments at 25 and 50 days after transplanting. Irrigation was done very carefully when needed to maintain the water stress according to the treatments and weeding was done regularly.

\section{Plant materials and plant growth}

To simulate the conditions of the local farming in Khulna region, 27 days old rice seedlings in regular cultivation Banglamoti (BRRI dhan 50), Vittiatash (BRRI dhan 28 selected) and Atash balam (BRRI dhan 28) were selected for transplanting into the pots. Three seedlings were transplanted in each pot which were arranged according to completely randomized design (CRD).

\section{Treatments}

In growth experiment, plants were subjected to five degrees of water stresses: $T_{1}=$ pots containing soil are ponded with water up to $5 \mathrm{~cm}$ above the soil surface, $\mathrm{T}_{2}=$ pots containing soil are ponded with water up to $3 \mathrm{~cm}$ above the soil surface, $\mathrm{T}_{3}=$ pots containing soil are saturated with water, $\mathrm{T}_{4}=$ soils in the pot contain water @ of $75 \%$ of saturation, $\mathrm{T}_{5}=$ soils in the pot contain water @ of $50 \%$ of saturation. Each treatment was replicated three times. 


\section{Measurement of agronomic yield and yield components}

Data on some morphological parameters such as plant height, tiller number, panicle number, and dry weight; yield attributes such as grain panicle ${ }^{-1}$, grain weight panicle $^{-1}, 1000$ grain weight, and harvest index were measured according to standard methods (Jahan et al., 2013). Two physiological characteristics like Water Use Efficiency (WUE), Relative Water Content (RWC) were recorded by following methods.

\section{Relative Water Content (RWC) estimation}

After collecting the leaves from the top, the RWC was calculated according to the following formula:

$\mathrm{RWC}=\frac{F W-D W}{T W-D W} \times 100$

Where, FW = fresh weight of leaves, TW = turgid weight of leaves, DW = dry weight of leaves

To avoid moisture loss from the leaves, the FW was taken as soon as possible after leaf collection. For obtaining the TW, the leaves were kept into a container filled with distilled water for 12 hours until the leaves reach a constant weight which was considered as $100 \%$ hydration. The TW was determined immediately after removing the leaves from water. The DW was taken after oven drying of fully turgid leaves for 48 hours at $70^{\circ} \mathrm{C}$ (Turner, 1986).

\section{Water Use Efficiency (WUE) estimation}

WUE was calculated as total dry weight divided by total amount of transpiration for each water treatment. WUE was calculated by using the following formula after observing the amount of water loss from the potson daily basis.

$$
W U E=\frac{\mathrm{W}_{2}-\mathrm{W}_{1}}{\text { STranspiration }}
$$

Where, $\mathrm{W}_{2}$ and $\mathrm{W}_{1}$ are the total plant dry weights after $2^{\text {nd }}$ and $1^{\text {st }}$ harvest respectively. Water stresses were imposed by simply weighing the soil added to the pot (dry weight), the amount of water started with and all other objects (weight of pot, etc.). Finally, weighing each pot once a week to measure evaporation and add evaporated water.

\section{Statistical Analysis}

The collected data were taken under the analysis of variance (ANOVA) using Minitab's ANOVA (version 17.0) and Duncan's New Multiple Range Test (DNMRT) was used to compare treatments.

\section{RESULTS AND DISCUSSION}

\section{Effect of water stress on morphological parameters}

The morphological characteristics of three rice varieties were tested at different water stressed condition are presented in Fig. 1. All the morphological results of tested rice 
varieties reduced significantly $(\mathrm{p}<0.001)$ due to water stress except plant height. Fig. 1(a) represents that plant height was almost similar regardless of the water stress as well as three rice varieties. In this case, Banglamoti showed highest plant height $(66.33 \pm 1.26 \mathrm{~cm})$ under $T_{3}$ and the lowest $(45.17 \pm 4.25 \mathrm{~cm})$ under $T_{5}$ treatment. Plant dry weight reduced progressively with the increment of stressed condition Fig. 1(b).

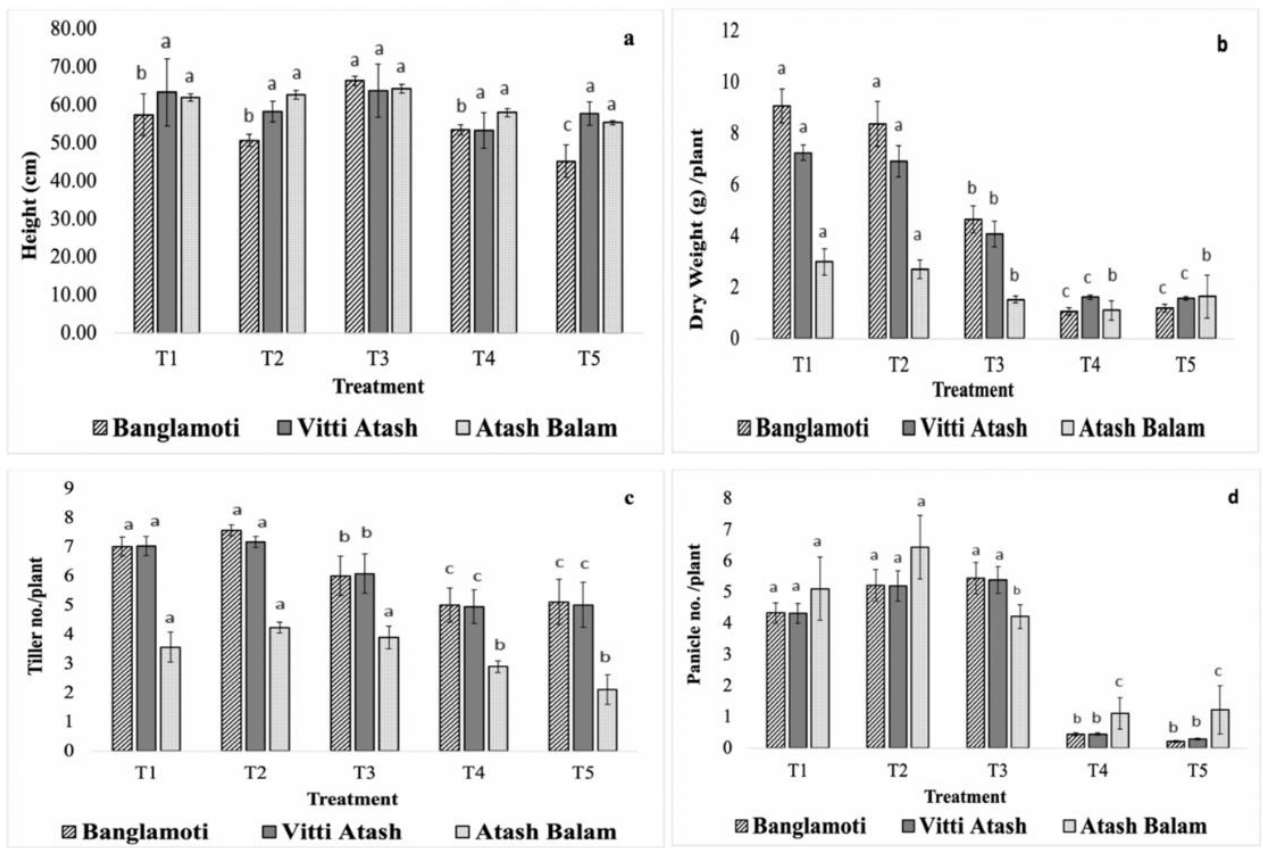

Fig. 1. Effects of water stress on (a) plant height, (b) dry weight, (c) tiller number, (d) panicle number (Each bar represents the average value of three replication, vertical lines above each bar indicates standard deviations, and different letters above the bars indicate the significant differences $(\mathrm{p}=0.05)$. Here, $\mathrm{T}_{1}=5 \mathrm{~cm}$ standing water; $\mathrm{T}_{2}=3 \mathrm{~cm}$ standing water; $\mathrm{T} 3=$ saturated condition; $\mathrm{T}_{4}=75 \%$ and $\mathrm{T}_{5}=50 \%$ of saturation)

Banglamoti showed the maximum dry weight $\left(9.07 \pm 0.66 \mathrm{~g}_{\text {plant }}{ }^{-1}\right)$ with $\mathrm{T}_{1}$ treatment though it is not significantly higher than Vittiatash and on the other hand, in case of Atash balam plant dry weight was comparatively very low under $\mathrm{T}_{1}, \mathrm{~T}_{2}$ and $\mathrm{T}_{3}$ treatments than the other two varieties. Water stress did not produce any significant change in tiller number plant ${ }^{-1}$ in case of each rice variety (Fig. 1c) but tiller numbers of Banglamoti and Vittiatash were almost similar and quite higher than that of Atash balam in every treatment. (Fig. 1d) shows that the maximum panicle number $\left(6.44 \pm 1.02\right.$ plant $\left.^{-1}\right)$ was found in Atash balam rice under $\mathrm{T}_{2}$ whereas Banglamoti and Vittiatash did not show any significant change in panicle number up to saturation. Panicle initiation was drastically reduced at severe water stress irrespective of the rice varieties studied. 
Our experimental results revealed that, water stress had no effects on the height of rice varieties and the observed results can be compared with Khairi et al. (2015) who run an experiment on rice under different water level and found the similar results. On the other hand, Zubaer et al. (2007) stated an inverse relation between plant height and water stress. Dry weight of three rice varieties decreased almost sequentially with increasing water stress (Fig. 1b). The process of oxidative deterioration due to water stress causes cell damage and reduction of nutrient uptake, photosynthesis rate and leaf area which might be responsible for the decrease in plant dry matter under lower soil moisture. The finding was also in accordance with Zubaer et al. (2007), who observed a decrease in shoot dry matter of Aman rice with increasing water stress. The soil moisture deficiency at a severe rate caused a reduction of tillers production and panicle number regardless of the three genotypes which may be caused by the reduction of assimilates production under water stress and our findings were similar with Sokoto and Muhammad, (2014). Akram et al. (2013) also found a decrease in panicle number in three basmati rice cultivars under water deficit stress.

\section{Effect of water stress on yield of three rice varieties}

The yields of three rice varieties influenced by different water level are presented in Fig. 2. The observed yield characteristics insignificantly differed with different water level among the rice varieties but it was noticeable that there were no yields below the saturation level in all varieties tested. The maximum grain plant $^{-1}(49.67 \pm 7.95)$ and grain weight plant $^{-1}(0.96 \pm 0.17 \mathrm{~g})$ were observed under $\mathrm{T}_{3}$ in Vittiatash. Banglamoti and Atash balam were in the second and third position, respectively, in both the cases Fig. 2(a, b).

From Fig. 2(c) it is seen that Vittiatash rice variety had the highest 1000 grain weight $(18.70 \pm 4.32 \mathrm{~g})$ at $\mathrm{T}_{3}$ and the lowest $(16.19 \pm 2.73 \mathrm{~g})$ at $\mathrm{T}_{1}$ but the values did not differ significantly from Banglamoti and Atash balam. The maximum 1000 grain weight of Banglamoti and Aatshbalam was calculated under $\mathrm{T}_{1}$ and $\mathrm{T}_{2}$, respectively. Fig 2(d) represents the effects of water stress on harvest index (HI) of three rice varieties. Among the rice varieties studied, the Vittiatash rice showed the highest HI than the other varieties of rice with $\mathrm{T}_{3}$ which was $(0.50 \pm 0.06)$ and Atash balam was in the lowest position in all the treatments. However, treatment did not show any significant effect on the specific rice variety.

The yield parameters were adversely affected under water stressed condition in such an extent that, no yields were observed below the saturation level. Several researches on rice plant also explained the decrease of grain number panicle ${ }^{-1}$, grain weight panicle $^{-1}, 1000$ grain weight with increasing moisture stress (Sokoto and Muhammad, 2014; Khairi et al., 2015; Yang, et al.,2019). In some cases, the drastic reduction of grain number (up to 50\%) was also found (Sarvestani et al., 2008). The reason of decrement of grain production can be narrated as, water stress reduced the starch accumulation capacity of endosperm into grain by inhibiting photosynthesis rate and 


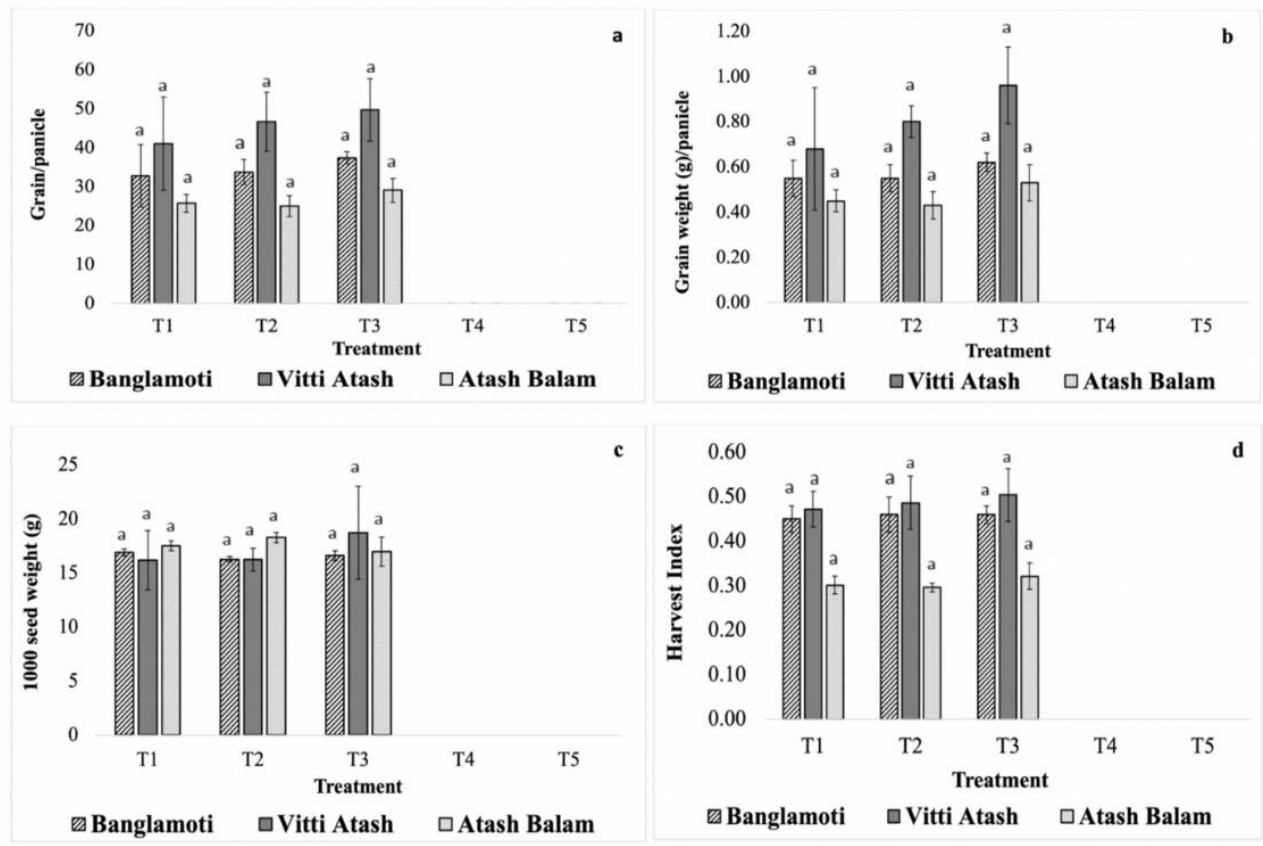

Fig. 2. Effects of water stress on yield and yield contributing characteristics of three rice varieties (a) grain content plant ${ }^{-1}$ (b) grain weight panicle ${ }^{-1}$ (c) 1000 grain weight (d) harvest index at different water stress (Each bar represents the average value of three replication, vertical lines above each bar indicates standard deviations, and different letters above the bars indicate the significant differences $(\mathrm{p}=0.05)$. Here, $\mathrm{T}_{1}=5 \mathrm{~cm}$ standing water; $\mathrm{T}_{2}=3 \mathrm{~cm}$ standing water; $\mathrm{T}_{3}=$ saturated condition; $\mathrm{T}_{4}=75 \%$ and $\mathrm{T}_{5}=$ $50 \%$ of saturation)

nutrient uptake which affected rice yield which was similar with the findings of Zhang et al. (2018). Among the different rice varieties studied, weight of 1000 grain were different in different moisture level and Vittiatash performed better in yield than that of Banglamoti and Atash balam. On the other hand, in spite of being a water loving plant, the highest amount of water level $(5 \mathrm{~cm})$ did not show highest production and grain yield increased from $T_{1}$ to $T_{3}$. So, from the experiment, it was clear that, rice need optimum water for its maximum growth and yield though the need of water depends on varieties. At the water levels below fully saturation (50\% and $75 \%$ saturation), there were no yield and above saturation $(5 \mathrm{~cm}$ and $3 \mathrm{~cm}$ water level), the yields were lower than that of saturated condition. The principal reasons behind the maximum grain yield were- proper oxidation mechanism, photosynthesis, sufficient nutrient uptake and increase in translocation of assimilates to the grain under saturation level.

The harvest index (HI) value is a very important indicator of production efficiency which indicates the proper translocation of sufficient assimilates to the grain. The 
reason of decrease in $\mathrm{HI}$ value could be explained as water stress inhibit nutrient supply and increase the yield of empty grain. In our experiment, the results suggested that soil water condition above saturation did not affect harvest index as well as yield and it was clear that, the three rice varieties showed different HI values under the experimental water treatments. The result was in agreement with the findings of Zubaer et al. (2007) and Khairi et al. (2015), who observed the highest HI under well irrigated varieties compared to that of grown under water stressed condition. They also stated that, the rate of reduction of HI largely influenced by the tolerance level of rice genotypes and soil moisture level.

\section{Effect of water stress on physiological characteristics of three rice varieties \\ Relative Water Content (RWC)}

The effects of water stress on relative water content (RWC) of three rice varieties are presented in Fig. 3a. From the figure, it is clear that the RWC of three rice varieties followed the similar decreasing trend with the increment of water stress and in each variety $\mathrm{T}_{5}$ showed the lowest RWC. Banglamoti, Vittiatash and Atash balam showed significantly $(\mathrm{p}<0.001)$ the maximum RWC $(73.62 \pm 1.71,76.45 \pm 1.80$ and $76.72 \pm 4.44 \%$ respectively) under $\mathrm{T}_{1}$ condition than the other water treatments though Banglamoti did not produce any significant reduction in RWC until saturation.

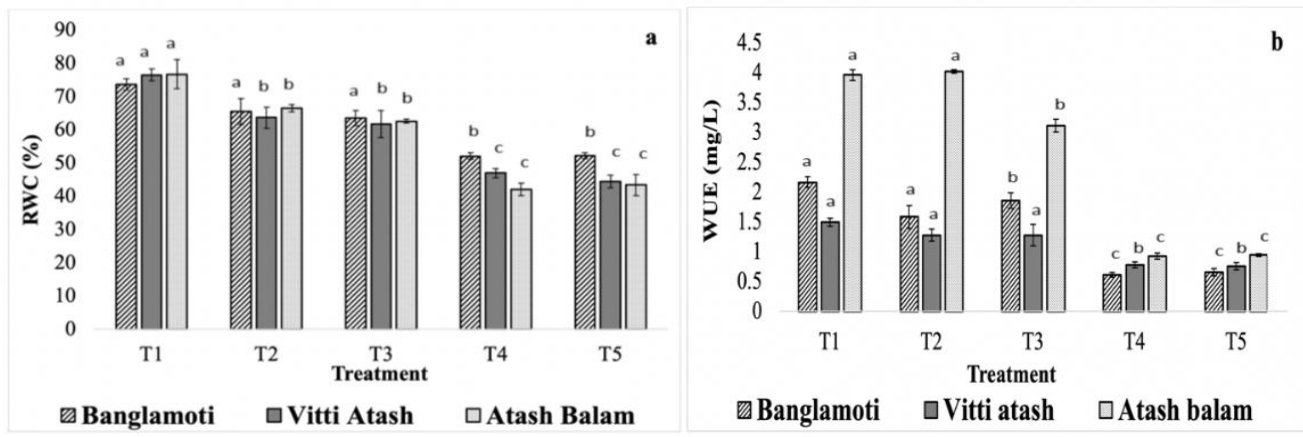

Fig. 3. Effects of water stress on (a) relative water content and (b) water use efficiency of three rice varieties (Each bar represents the average value of three replication, vertical lines above each bar indicates standard deviations, and different letters above the bars indicate the significant differences $(\mathrm{p}=0.05)$. Here, $\mathrm{T}_{1}=5 \mathrm{~cm}$ standing water; $\mathrm{T}_{2}=3 \mathrm{~cm}$ standing water; $\mathrm{T}_{3}=$ saturated condition; $\mathrm{T}_{4}=75 \%$ and $\mathrm{T}_{5}=50 \%$ of saturation)

\section{Water Use Efficiency (WUE)}

The results of Fig. 3b represents that the change in WUE varied with water level and rice varieties and decreased with the increasing rate of water stress. The WUE of Atash balam was higher in each case and the significantly $(\mathrm{p}<0.001)$ higher value was observed in Atash balam under $\mathrm{T}_{2}\left(4.03 \pm 0.03 \mathrm{mgl}^{-1}\right)$ though $\mathrm{T}_{1}$ and $\mathrm{T}_{2}$ were statistically similar. The maximum WUE of Banglamoti $\left(2.17 \pm 0.09 \mathrm{mgl}^{-1}\right)$ and Vittiatash $\left(1.5 \pm 0.07 \mathrm{mgl}^{-1}\right)$ were found under $\mathrm{T}_{1}$ treatment. 
RWC is considered as one of the important and easily measurable parameters in agriculture that is very useful to identify the drought tolerance of plants. The high RWC value expressing the withstand capacity of plant under water stressed condition than the drought-sensitive species with low RWC (Boutraa et al., 2010). Our results were in accordance with Zulkarnain et al. (2009) and Akram et al. (2013), who revealed the decreased of RWC in rice grown under water stress treatment. By using RWC value as a criterion for finding out drought tolerance, the three rice varieties might be considered drought-tolerant up to saturated condition as the RWC values are close for $T_{1}, T_{2}$ and $T_{3}$ but below this level, a noticeable decrease were observed. This result can be compared with the experimental outcome of Chelah et al. (2011), who did not find out any adverse impact on RWC in rice plant at saturation level.

Water use efficiency (WUE) can be considered as one of the major physiological characteristics of rice plant that is obtained by the ratio of plant dry matter to transpiration rate which determine the yield under limited condition of water (Jaafar et al., 2000; Boutraa et al., 2010). So, it can be said that, Atash balam was the most water consuming variety, followed by Banglamoti and Vittiatash, respectively. Under the most stressed condition i.e. $\mathrm{T}_{4}$ and $\mathrm{T}_{5}$ treatments, all varieties showed very low and no significant change in WUE. The result showed that WUE was not affected at higher water content in any one of the studied rice variety. Under water stressed condition, the recession of water is responsible for stress at these treatments and results in low WUE. This inverse relationship between water stressed condition and WUE was also confirmed by earlier research (Shangguan et al., 2000; Boutraa et al., 2010) using wheat as experimental plant, but highly depends on variety. On the other hand, Akram et al. (2013) found opposite results by an experiment on rice plant and stated that, WUE was enhanced significantly under moisture stress.

\section{CONCLUSION}

The response of three rice cultivars under different water treatments was investigated and yield reduction was observed in each case under water deficient condition. No yield was found in the soil water level below the saturation for all the rice varieties. The vegetative growth and dry weight of the studied plants were higher under $5 \mathrm{~cm}$ standing water level but grain yields and harvest index were found higher under saturated condition. The relative water content and water use efficiency also decreased with decreasing moisture level. Among the varieties, Vittiatash can be evaluated as most potential variety with the maximum grain content per panicle, 1000 grain weight and harvest index by consuming minimum quantity of water under saturated water treatment. Finally, it can be concluded that there were no significant differences in yield of rice grown under the soil flooding with $5 \mathrm{~cm}$ or $3 \mathrm{~cm}$ depth, as a result approximately $2 \mathrm{~cm}$ irrigation water can be curtailed easily without any adverse impact on rice production. 


\section{ACKNOWLEDGEMENT}

We greatly acknowledge Khulna University Research Cell for providing fund for this research work.

\section{REFERENCES}

Akram, H.M., Ali, A., Sattar, A., Rehman, H.S.U. and Bibi, A. (2013). Impact of water deficit stress on various physiological and agronomic traits of three basmati rice (oryza sativa) cultivars. Journal of Animal and Plant Sciences, 23(5): 1415-1423.

BARC. (2012). Fertilizer Recommendation Guide, Farmgate, Dhaka. Soils publication no 41: 125 .

Basu, S., Roychoudhury, A., Saha, P.P. and Sengupta, D. (2010). Differential antioxidative responses of indica rice cultivars to drought stress. Plant Growth Regulation, 60: 51-59.

Boutraa, T., Akhkha, A., Khaliq, A., Al-Shoaibi, A. and Alhejeli, A.M. (2010). Effect of water stress on growth and water use efficiency (WUE) of some wheat cultivars (Triticum durum) grown in Saudi Arabia. Journal of Taibah University for Science, 3: $39-48$.

BBS. (2002). Bangladesh Bureau of Statistics. Statistical Pocketbook 2000, Bangladesh Bureau of Statistics. Ministry of Planning. Bangladesh, Dhaka.

Chelah, M.K.B., Nordin, M.N.B., Musliania, M.I., Khanif, Y.M. and Jahan, M.S. (2011). Composting increases bris soil health and sustains rice production on bris soil. Science Asia, 37: 291-295.

IRRI. (2012). International Rice Research Institute, Annual Report for 2011. Los Banos, Philippines.

Jaafar, M.N. Saad, P. and Arjunan, S.N.V. (2000). A computational model for water use efficiency in rice production. Journal Teknologi Maklumat, 12(1): 1-13.

Jahan, M.S., Nozulaidi, M.B.N., Moneruzzaman, M.K., Ainun, A. and Husna, N. (2014). Control of plant growth and water loss by a lack of light-harvesting complexes in photosystem-II in Arabidopsis thaliana ch1-1 mutant. Acta Physiologiae Plantarum, 36(7): 1627-1635.

Jahan, M.S., Khanif, Y.M. and Sinniah, U.R. (2013) Effects of low water input on rice yield: Fe and Mn bioavailability in soil. Pertanika Journal of Tropical Agriculture, 36: 27-34.

Khairi, M., Nozulaidi, M., Afifah, A. and Jahan, M.S. (2015). Effect of various water regimes on rice production in lowland irrigation. Australian Journal of Crop Science, 9(2): 153-159.

Materu, S., Shukla, S., Sishodia, R., Tarimo, A. and Tumbo, S. (2018). Water use and rice productivity for irrigation management alternatives in Tanzania. Water, 10(8): 1018.

Sarvestani, Z.T., Pirdashti, H., Sanavy, S.A. and Balouchi, H. (2008). Study of water stress effects in different growth stages on yield and yield components of different rice (Oryza sativa L.) cultivars. Pakistan Journal of Biological Science, 11(10): 1303-1309. 
Shangguan, Z.P., Shao, M.A. and Dyckmans, J. (2000). Nitrogen nutrition and water stress effects on leaf photosynthetic gas exchange and water use efficiency in winter wheat. Environmental and Experimental Botany, 44: 141-149.

Sokoto, M.B. and Muhammad, A. (2014). Response of Rice Varieties to Water Stress in Sudan Savannah, Nigeria. Journal of Biosciences and Medicines, 2: 68-74.

Suriyan, C., Yoo, Y.S. and Supaibulneatana, K. (2010). Water deficit stress in the productive stage of four indica rice (Oryza sativa L.) genotypes. Pakistan Journal of Botany, 42(5): 3387-3398.

Tuna, A.L., Kaya, C. and Ashraf, M. (2010). Potassium sulfate improves water deficit tolerance in melon plants grown under glasshouse conditions. Journal of Plant Nutrition, 33(9): 1276-1286.

Tuong, T.P., Bouman, B.A.M. and Mortimer, M. (2005). More rice, less water-integrated approaches for increasing water productivity in irrigated rice-based systems in Asia. Plant Production Science, 8(3): 231-241.

Turner, N.C. (1986). Crop Water Deficits: A Decade of Progress. Advances in Agronomy, 39: $1-51$.

Yang, X., Wang, B., Chen, L., Li, P. and Cao, C. (2019). The different influences of drought stress at the flowering stage on rice physiological traits, grain yield, and quality. Scientific Reports, 9: 3742.

Zhang, J., Zhang, S., Cheng, M., Jiang, H., Zhang, X., Peng, C., Lu, X., Zhang, M. and Jin, J. (2018). Effect of drought on agronomic traits of rice and wheat: A meta-analysis. International Journal of Environmental Research and Public Health, 15(5): 839.

Zubaer, M.A., Chowdhury, A.K.M.M.B., Islam, M.Z., Ahmed, T. and Hasan, M.A. (2007). Effects of water stress on growth and yield attributes of Aman rice genotypes. International Journal of Sustainable Crop Production, 2(6): 25-30.

Zulkarnain, W.M., Ismail, M.R., Ashrafuzzaman, M., Saud, H.M. and Haroon, I.C. (2009). Growth, physiological and biochemical responses of Malaysia rice cultivars to water stress. Pertanika Journal of Tropical Agricultural Science, 32(2): 323-333. 